\title{
Energy and urban built form: an empirical and statistical approach
}

\author{
Philip Steadman ${ }^{1}$, lan Hamilton ${ }^{1}$ and Stephen Evans ${ }^{2}$ \\ ${ }^{1}$ UCL Energy Institute, University College London, Central House, 14 Upper Woburn Place, London \\ WC1H ONN, UK \\ E-mails: j.p.steadman@ucl.ac.uk and i.hamilton@ucl.ac.uk \\ 23 Figs, Blachier, Bozas F-07410, France \\ E-mail:steve@3figs.com
}

\begin{abstract}
The geometrical forms of buildings have important effects on their use of energy. These relationships are explored at the scale of the entire non-domestic building stock of London. A three-dimensional digital model of the city is used to make a series of geometrical measures: building volume, exposed surface area (walls plus roof) and plan depth. These are compared with figures for the consumption of gas and electricity published by the UK Department of Energy and Climate Change (DECC). The comparisons are made at different levels of spatial aggregation, from boroughs to census districts. Strong correlations are demonstrated between exposed surface area and both gas and electricity use. The analysis also provides some evidence of a sharp increase in electricity use in districts with buildings whose depth in plan exceeds $14 \mathrm{~m}$ (in which air-conditioning and permanent artificial lighting are typically required). A multiple regression model is used to measure the contribution of these effects to total energy use, as compared with floor area, activities and number of employees.
\end{abstract}

Keywords: building form, building geometry, building stock, electricity use, energy demand, exposed surface area, gas use, non-domestic, plan depth

\section{Introduction}

Two hypotheses are tested on the relationship of three-dimensional urban morphology to the use of energy in buildings. The focus is on nondomestic buildings in Greater London. The first hypothesis is:

(H1): That energy use for space heating is correlated with the total exposed surface area of buildings.

The second hypothesis is:

(H2): That there is an effective threshold value for the depth of multi-storey buildings in plan, above which energy use for air-conditioning and artificial lighting rises sharply.

Similar hypotheses have been proposed and investigated by other authors. The present study breaks new ground by taking an empirical and statistical approach that is applied to all buildings in the non-domestic stock across the whole of London.

\section{Exposed surface area and energy use for heating: previous work}

The first hypothesis (H1) is expected to be true in a temperate climate like that of the UK on the strength of the basic physics of heat loss. Ratti, Baker, \& Steemers (2005) studied a range of geometrical measures of urban built form in relation to energy use, including the ratio of exposed surface area to volume. They took $400 \times 400 \mathrm{~m}$ sample areas in three cities - London, Berlin and Toulouse - and represented their threedimensional forms with digital elevation models (DEMs). (The London sample was in the Borough of Camden, centred on Tottenham Court Road.) They modelled energy use with the LT (Lighting, Thermal) simulation package, using default values for everything other than geometrical parameters, with the intention 
of making comparisons on an equal basis rather than estimates of actual consumption.

Salat (2009) studied the relationship of surface to volume with energy use for space heating in the residential stock of Paris, again using DEMs to represent three $500 \times 500 \mathrm{~m}$ zones with distinctive building 'typologies' of different dates, specifically two types of courtyard pattern, historic and modern, and a development of freestanding Modernist blocks. The energy use was modelled and the estimates compared with actual consumption levels for Parisian residential buildings generally. More recently, members of the LSE Cities centre at the London School of Economics have also studied residential heating energy use and urban morphology (Rode, Keim, Robazza, Viejo, \& Schofield, 2013). This research took $500 \times 500 \mathrm{~m}$ sample areas in four cities - London, Paris, Berlin and Istanbul - and represented not the actual geometry of the buildings in question, but an idealization of the characteristic forms of the most frequently occurring types. The study area for London consisted mostly of terraced buildings. Energy use for heating was then modelled and compared with several parameters including density, building height and the ratio of surface to volume. The results of all these studies are discussed below.

\section{Virtual London model}

The research reported here relates as mentioned to the entirety of London. A three-dimensional digital model of the metropolis is used which includes all buildings out to the M25 orbital motorway (Figure 1). This 'Virtual London' is constructed from building footprint data in Ordnance Survey maps (Mastermap Topography layer) combined with remotely sensed information on heights obtained by light detection and ranging (LiDAR) methods (Batty \& Hudson-Smith, 2005). The LiDAR measurements are taken on a $1 \mathrm{~m}$ grid spacing and can therefore represent internal courts and setbacks on upper floors. The resulting vertical dimensions should be somewhat more accurate than in DEMs where heights are estimated from numbers of storeys. In both cases, roofs are taken to be flat, but in Virtual London the heights for buildings with pitched roofs are averaged from all LiDAR values falling within the given footprint polygon. Virtual London comprises some 3.2 million blocks, many of which are fragmentary parts of buildings. A small block, for example, might correspond to a lift tower, an entrance porch or a back extension. The Mastermap data were combined with the Generalised Land Use Database (HM Government, 2013), making it possible to distinguish domestic from non-domestic buildings, and to categorize the non-domestic buildings as office, retail, warehouse, etc. (There are weaknesses in the data in the categorization of buildings that contain both domestic and non-domestic premises.)

Volumes of blocks are given simply by multiplying footprint polygon areas by heights. For analysis the volumes were grouped into a series of approximately logarithmic size bands: 0-3, 4-10, 11-30, 31-100 m³ , etc. Virtual London has no information on numbers of storeys. In

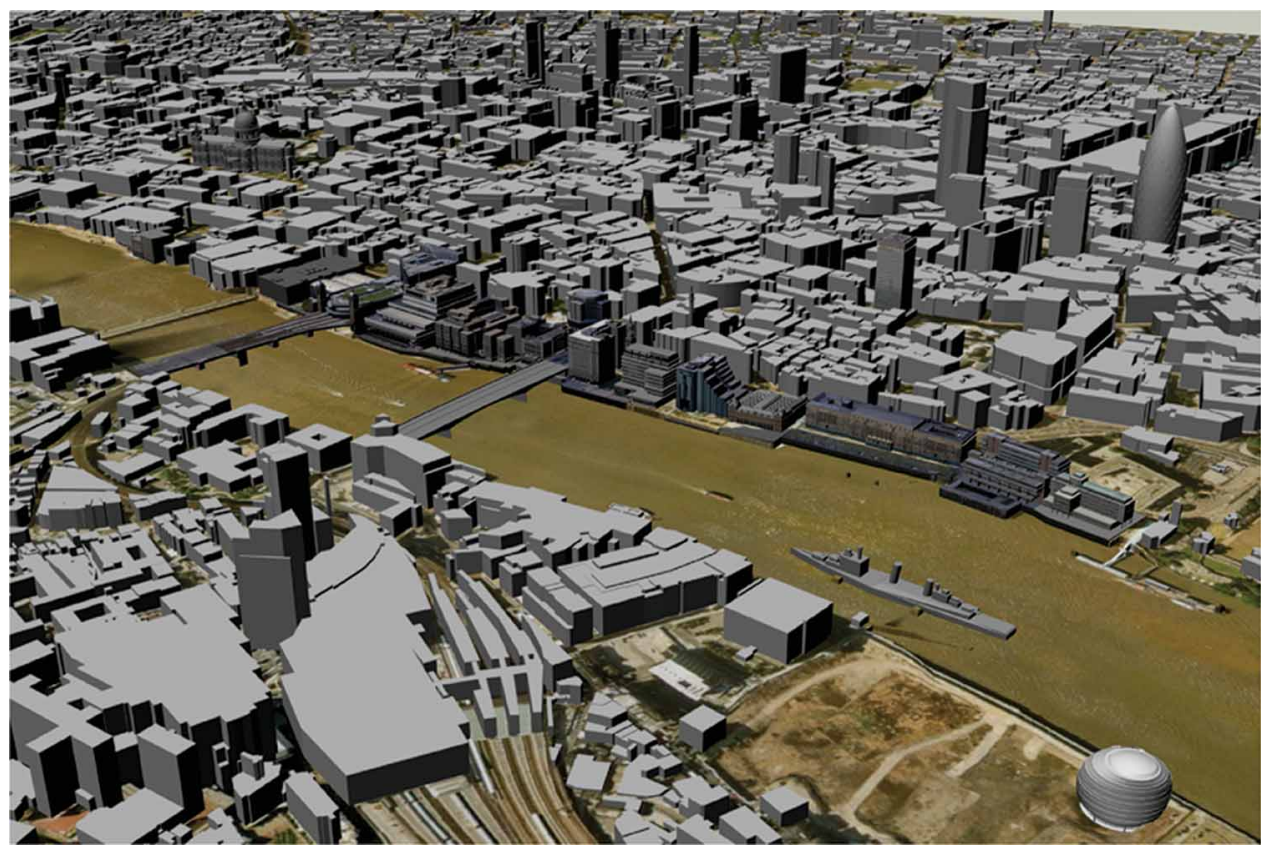

Figure 1 The Virtual London model 
order to obtain estimates of floor areas, volumes were therefore divided by a standard assumed value for storey height of $3.5 \mathrm{~m}$. This is somewhat greater than the typical value of $3.0 \mathrm{~m}$ for modern offices to allow for taller ceilings in factories, warehouses and large shops. This assumption was guided by an analysis of storey heights in a sample of some 3500 buildings in British towns made in the 1990s (Brown, Rickaby, Bruhns, \& Steadman, 2000); however, the assumption of a single default value clearly means that the floor area estimates will be approximate only.

For calculating exposed surface, roof areas are taken to be equal to footprint areas. Measuring the areas of exposed walls is more complicated, since these need to be distinguished automatically from internal walls between adjoining blocks, some of which will be actual party walls between properties. Such topological relationships can be dealt with in geographical information system (GIS) software by categorizing the walls belonging to building footprints as 'children' of their 'parent' polygons. The walls can then be assigned heights; and by analyzing the spatial relationships of the polygon in question to adjoining polygons, it is possible to determine whether the walls face courtyards or face outwards - and so are exposed in both cases - or are internal. Where a wall divides buildings or blocks of different heights, it may be an internal wall on the lower floors or an exposed wall on the upper floors (Figure 2). The section of wall in the darker tone where the two blocks at the left of Figure 2 meet, for example, is not exposed, but the parts above and to the left of this are exposed. The analysis takes care of such situations. All these exposed wall areas need to be summed and added to the roof areas to obtain total exposed surface area. (It is possible that some small light wells might be omitted from the

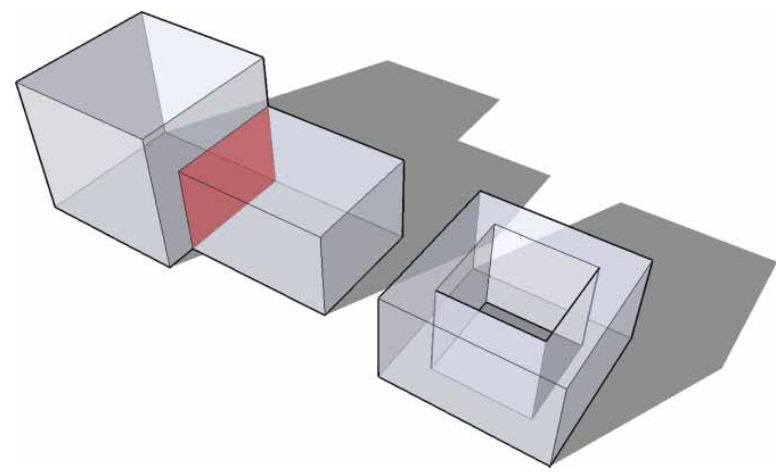

Figure 2 Three extruded polygon buildings are shown in a three-dimensional view with the buildings having semitransparent walls (and casting a shadow). The left-most building is adjacent to the middle building, and part of their shared wall (darker tone) is not exposed to the elements. Since these two buildings differ in height and depth, there are other sections of this wall that are exposed. All other walls (including the inner courtyard walls of the right-most building) contribute to the exposed surface area of the building
Virtual London model, in which case the exposed areas could be underestimated. If so, such effects are expected to be minor.)

To measure the depths of buildings in plan, a method is used that was developed for and explained in a previous paper (Steadman, Evans, \& Batty, 2009). The total exposed wall area of each block is divided by the block's volume. This gives a value that would be exactly equal to half of plan depth in the case of an elongated detached block of simple rectangular form, should the areas of the long walls be counted but not the areas of the short end walls. (Of course, all wall areas are included in the present analyses.) The advantage of this method is that it can be applied to all shapes of plan, rectangular or otherwise, for which in many cases it is impossible to define a simple linear measurement of depth. Where groups of blocks are joined together to form 'buildings', the calculation takes account of their total volume in relation to their total exposed wall area.

It is worth emphasizing that the hypothesis about energy use and plan depth is only relevant to multistorey buildings, since single-storey buildings can be lit and ventilated from the roof. There are several activities that can occupy single-storey buildings with very deep plans, including factories, warehouses and 'big shed' superstores. Much work on energy use in the non-domestic building stock is predicated in the belief that a substantial fraction of that stock comprises office buildings. However, in England and Wales the total floor areas of shops, factories and warehouses are each of them greater than the total area of offices. This phenomenon of the deep plan singlestorey shed is revealed in the results presented below.

The measurements on Virtual London were aggregated geographically to lower level super output areas (LSOAs) and medium level super output areas (MSOAs) in order to make comparisons with energy data. These are spatial units designed by the UK Office of National Statistics (ONS) for census purposes. To give an idea of their size, in residential areas an LSOA would comprise between 400 and 1200 households and an MSOA between 2000 and 6000 households. On occasion, the building polygons straddled several output areas and in these cases, rather than split buildings, they were assigned completely to the area in which the greater part fell.

\section{Electricity and gas consumption data}

The energy data were drawn from a national database of annual electricity and gas consumption statistics, compiled by the UK Department of Energy and Climate Change (DECC) (2009). These are aggregated from individual gas and electricity meter point data for all meters in London, and published at two geographical scales: local authority and MSOA. 
The meters fall into different groups: daily and nondaily for gas, and half-hourly and non-half-hourly for electricity. For all electricity meters, annualized figures are derived from meter readings and classified into eight user groups, which are defined by the type of user (domestic or non-domestic), tariff type (standard or economy) and, for non-domestic meters, the amount of electricity used. For all gas meters, annualized figures are also derived from meter readings, but unlike electricity no further classification is made. Instead, gas meters are generally assumed to be 'domestic' if consumption is less than 73.2 $\mathrm{MWh} /$ year although for official statistics the DECC (2009) goes through a process of allocating as many meters as possible to their proper classes using address details. Due to issues of privacy, half-hourly electricity and some nondaily gas meters are not allocated to geographical units below local authority level. In 2007 this meant that only $28 \%$ of total non-domestic electricity use was allocated at the MSOA level. Most of these meters are non-halfhourly and generally characterized as smaller users (DECC, 2009). By contrast, for non-domestic gas demand, 97\% was allocated at the MSOA level.

It is possible therefore to separate non-domestic from domestic energy demand from these figures, but not to break them down any further by end uses. The levels of geographical aggregation create difficulties for any spatial analysis, and it would be very desirable to have complete figures at LSOA level. Further, the breakdown of energy demand by final end-uses for the non-domestic stock within the national statistics (DECC, 2012) is estimated by using a number of models with unknown parameters, and therefore is not used here. It is worth saying, however, that estimates suggest that there has been moderate change in consumption in the non-industrial stock over the past 15 years. Ideally, one would be able to go into the level of detail provided by Liddiard (2013), with sectoral estimates by final end use at room level. Given the limitations of the data, the current authors have carried out some broad-brush studies for both gas and electricity at the local authority scale. At the finer scales, this entailed working with non-domestic gas data allocated to MSOAs, since this excludes only $3 \%$ of meters. Non-domestic electricity data allocated to MSOAs have been used for exploratory and indicative purposes, even though these account for less than one-third of total consumption.

\section{Results}

Table 1 gives summary statistics for the morphological measures on non-domestic blocks across London. Note: these blocks are in many cases parts of buildings, thus the average values will be smaller than those for complete buildings. The mean value for the ratio of exposed wall to volume is 4.5 , implying a plan depth of $9 \mathrm{~m}$. This is the sort of dimension one could expect for naturally lit and ventilated buildings of domestic scale. (The typical depths in plan of British houses are around 7 m.) Figure 3 maps total volume; Figure 4 maps exposed surface area; Figure 5 maps building depth, which is obtained by dividing exposed wall area by volume. The data in the figures are for LSOAs in all cases.

A picture emerges of several small concentrations of very large, tall and deep buildings, with the remainder characterized by low-rise, shallower plan buildings. Building volume (Figure 3 ) is concentrated in the office areas of the City of London and along the River Thames, and in the industrial areas along the Lea River valley to the north and in Hounslow around Heathrow Airport to the west. Figure 4 shows that exposed area follows a similar pattern to volume, but with an increase around the outer edges of the metropolis. The mean value for surface to volume in LSOAs for the whole of London is 0.35 . For the borough of Camden, the value is 0.28 , indicating taller deeper buildings than in the metropolis generally. (This compares with a value of 0.216 obtained by Ratti et al. (2005) for their sample area in Camden, in which the buildings are large compared with much of the rest of the borough.) Figure 5 shows that deeper blocks - i.e. those with depths greater than $10 \mathrm{~m}$, shown in the

Table 1 Summary statistics for non-domestic built form parameters in London

\begin{tabular}{lrrrrr}
\hline Non-domestic buildings variable & Mean & SD & Median & Lower quartile & Upper quartile \\
\hline Footprint area per block $\left(\mathrm{m}^{2}\right)$ & 295.0 & 936.2 & 52.3 & 14.5 & 215.2 \\
Volume per block $\left(\mathrm{m}^{3}\right)$ & 2885.3 & 12043.6 & 310.7 & 47.3 & 1641.3 \\
Wall area per block $\left(\mathrm{m}^{2}\right)$ & 449.5 & 1023.6 & 136.0 & 35.8 & 420.9 \\
Mean half plan depth $($ volume/wall area) per block $(\mathrm{m})$ & 3.1 & 2.99 & 2.4 & 1.4 & 3.9 \\
Plan depth per block $(\mathrm{m})$ & 6.2 & 5.9 & 4.8 & 2.7 & 7.8 \\
Height per block $(\mathrm{m})$ & 6.5 & 5.2 & 5.8 & 3.1 & 8.2 \\
Floor space per block $\left(\mathrm{m}^{2}\right)$ & 901.7 & 3763.6 & 97.1 & 14.8 & 512.9 \\
\hline
\end{tabular}

Source: Data are derived from Virtual London. 


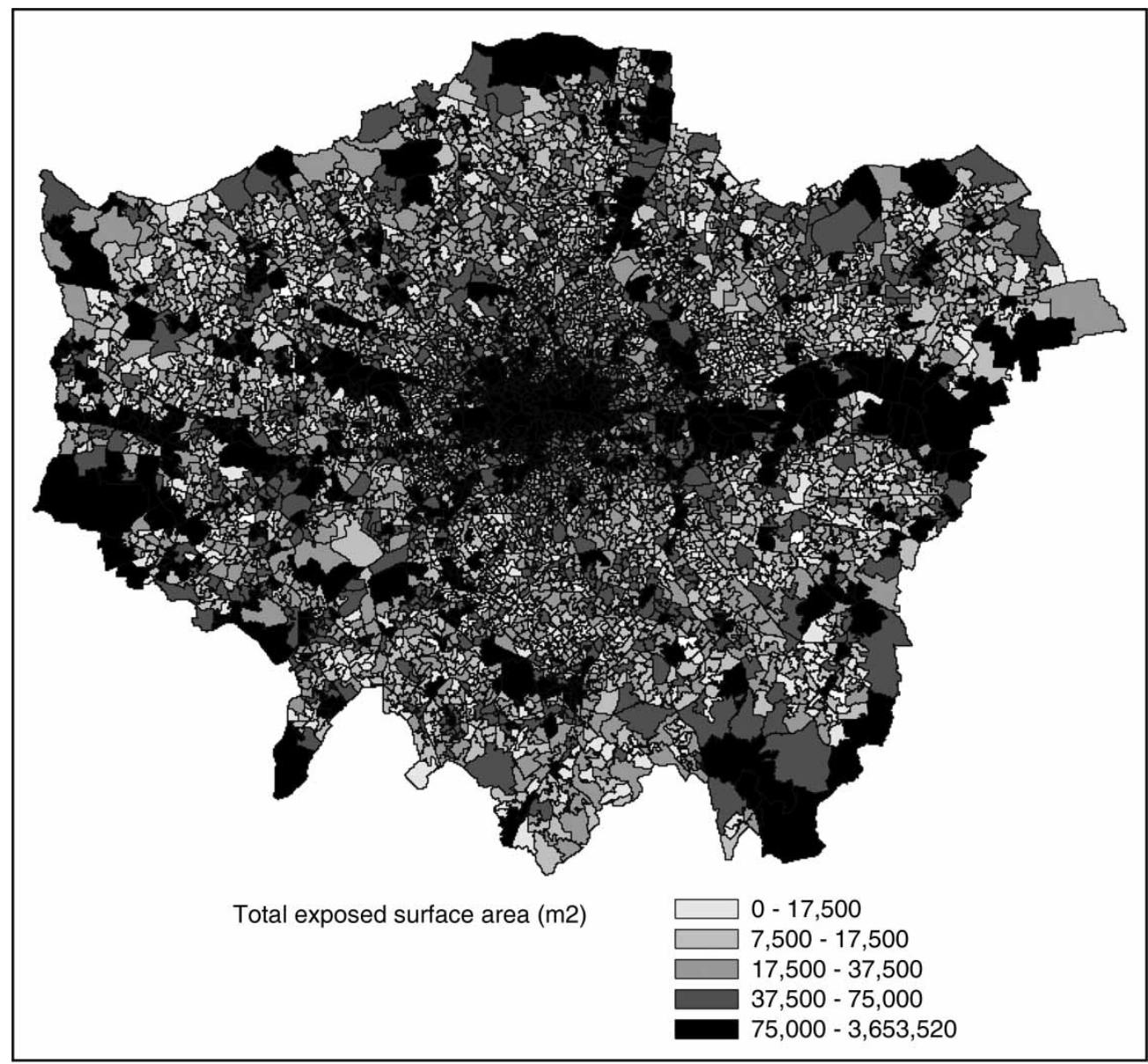

Figure 3 Total building volume $\left(\mathrm{m}^{3}\right)$ of non-domestic buildings for all lower level super output areas (LSOAs) in London

darkest tone - are found in central London and in the same industrial areas that have high building volume.

Figure 6 gives the distribution for the volumes of blocks, by size bands $\left(\mathrm{m}^{3}\right)$, for each of London's local authorities. This shows that boroughs such as Camden, Islington, Kensington and Chelsea, Southwark, Tower Hamlets, and Westminster have higher concentrations of larger blocks with volumes above $1000 \mathrm{~m}^{3}$. More than half of the built blocks in the City of London are above $3000 \mathrm{~m}^{3}$.

Table 2 gives means for non-domestic gas and electricity use in 2007 using local authority-level data, including consumption by meter and consumption per $\mathrm{m}^{2}$ of floor area. (The floor area estimates are gross external figures, so these intensities would be somewhat lower than those measured by net internal or gross internal area.) Figure 7 breaks down the energy intensity values per $\mathrm{m}^{2}$ into separate local authorities. Notice the particularly high values for electricity use in several boroughs with high concentrations of office activity: the City of London, Kensington and
Chelsea, Tower Hamlets (the location of the major Docklands office zone, including Canary Wharf), and Westminster. The City has the highest electricity intensity of all, at $287 \mathrm{kWh} / \mathrm{m}^{2}$, compared with a gas demand of $101 \mathrm{kWh} / \mathrm{m}^{2}$. Tower Hamlets has a comparatively low level of gas use $\left(66 \mathrm{kWh} / \mathrm{m}^{2}\right)$, suggesting that electricity may be being used extensively for space heating and cooling in Docklands. Harrow has the highest gas demand at $239 \mathrm{kWh} / \mathrm{m}^{2}$, compared with an electricity intensity of $95 \mathrm{kWh} /$ $\mathrm{m}^{2}$ : the borough has a number of industrial parks with large sheds along the M40/A40 corridor.

As mentioned, the consumption data are not broken down by end uses. Large-scale data on the construction characteristics for non-domestic buildings in the UK are severely limited. Although it is well understood that a number of non-morphological factors will directly affect the amount of energy consumed in a building (e.g. facade materials, proportion of glazing, heating and core services, information technology (IT) equipment, air-conditioning, and activity type), no such database exists that offers comprehensive or even indicative 


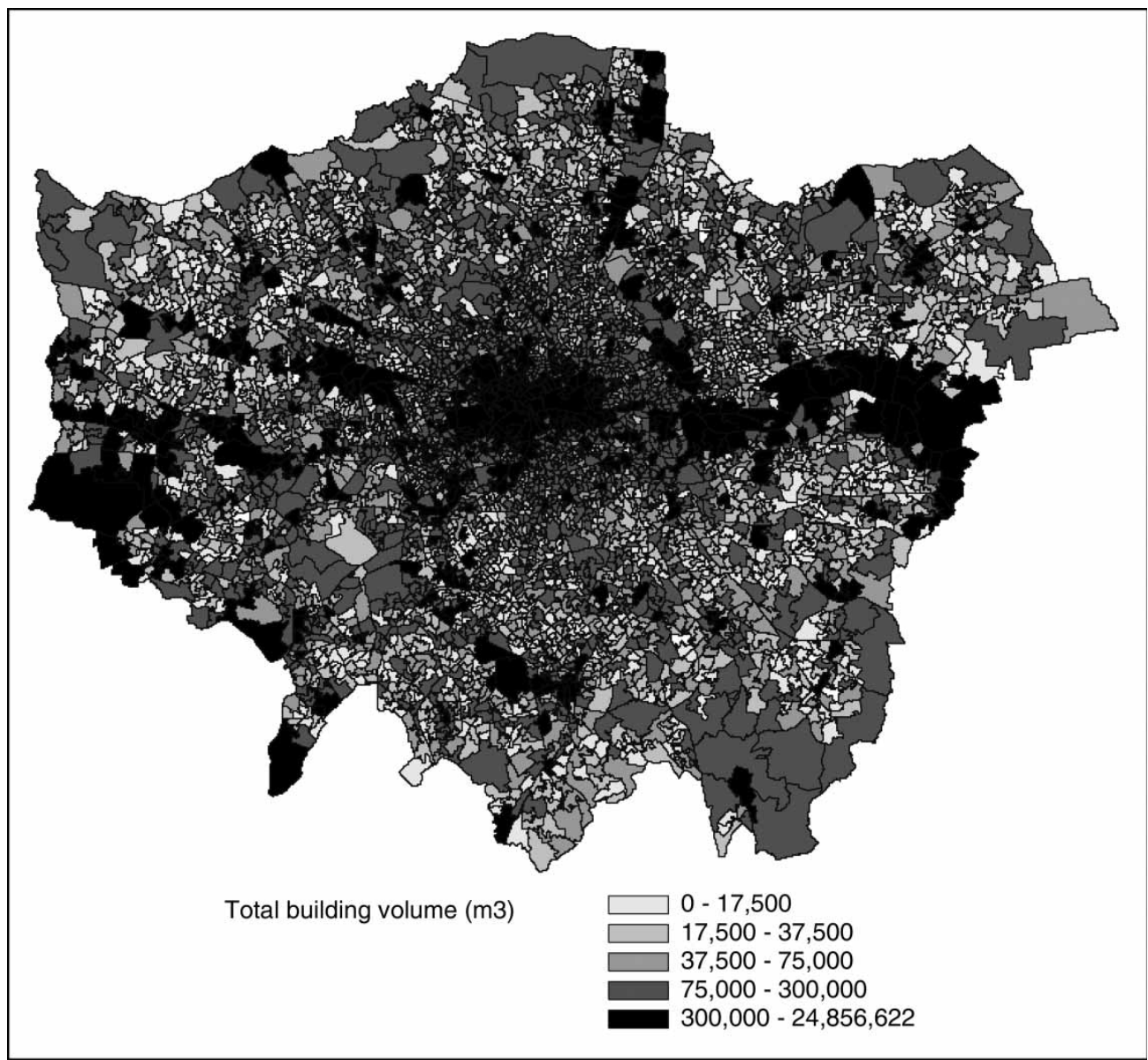

Figure 4 Total exposed surface area $\left(\mathrm{m}^{2}\right)$ of non-domestic buildings for all lower level super output areas (LSOAs) in London

details on these for London. One would, of course, expect that a significant fraction of the electricity use in the boroughs that are dominated by office activity would be accounted for by IT and computing equipment. This, along with lighting, would be contributing to the internal gains, and would further increase cooling demand. All this obviously complicates the relationship between energy use and plan depth in the office stock. As a result, although the morphological factors that relate to energy demand can be examined, it is not possible to control for all these other unknown factors. Analysis of such issues at the urban or borough scale would require end-use data that do not currently exist. Thus, one should be cautious of assigning too much significance to these relationships; nonetheless, they are indicative of expected patterns.

\section{Exposed surface area}

Figure 8 shows the correlations of total exposed surface area with mean annual gas and electricity

Table 2 Summary statistics for non-domestic energy in 2007 for London at local authority level

\begin{tabular}{|c|c|c|c|c|c|}
\hline Variable & Mean & SD & Median & Lower quartile & Upper quartile \\
\hline Mean electricity use (kWh/meter/year) & 73275 & 58472 & 54527 & 45061 & 77574 \\
\hline Mean electricity intensity $\left(\mathrm{kWh} / \mathrm{m}^{2} / \text { year }\right)^{\mathrm{a}}$ & 127.0 & 46.9 & 110.7 & 97.4 & 144.0 \\
\hline Mean gas use (kWh/meter/year) & 571352 & 292119 & 496590 & 358078 & 616865 \\
\hline Mean gas intensity $\left(\mathrm{kWh} / \mathrm{m}^{2} / \text { year }\right)^{\mathrm{a}}$ & 118.8 & 40.3 & 111.8 & 98.5 & 134.4 \\
\hline
\end{tabular}

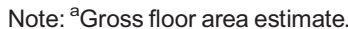




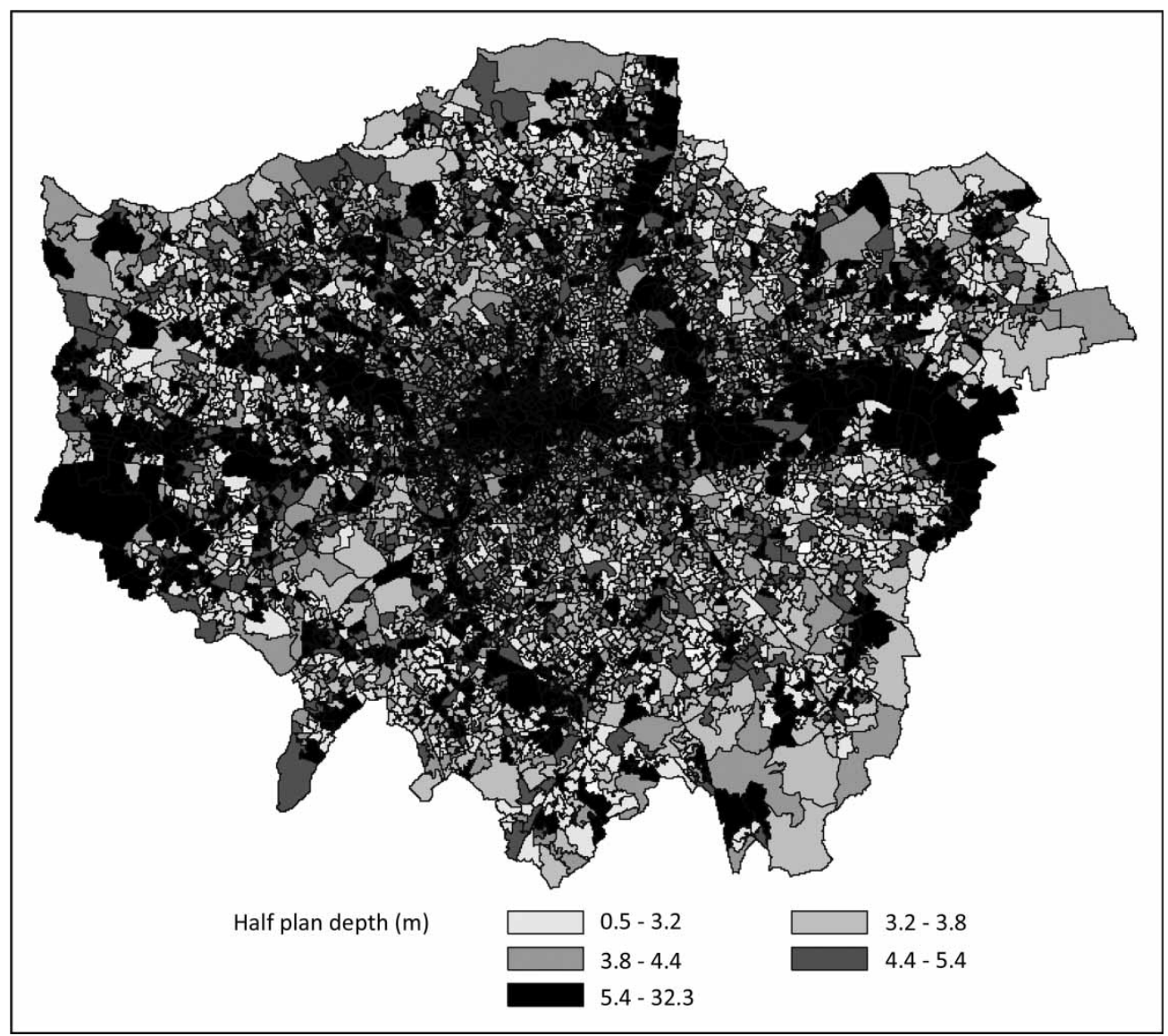

Figure 5 Average wall to volume ratio $(\mathrm{m})$, or half plan depth, of non-domestic buildings for all lower level super output areas (LSOAs) in London

demand per meter, respectively, for all non-domestic buildings in London. The Pearson correlation coefficients are given in Table 3 . The use of surface area was selected rather than the ratio of surface to volume. This is more appropriate when looking for effects relating to space heating demand, which would tend to be proportional to volume; and to compare surface to volume with energy use to volume would mean having the same denominator in both variables. As would be expected, the correlation of surface area to both gas and electricity use is significant $(p<0.001$ at the $95 \%$ level), with coefficients of 0.82 and 0.76 , respectively, showing that energy use does indeed increase with exposed surface area. This goes some way to confirming the first hypothesis, although not all of the energy demand can be attributed to the explanatory power of surface area due to lack of information on other building features. Gas is the dominant heating fuel in Britain; however, there is a large but unknown extent of electricity use for space heating in the nondomestic stock. There is also an expectation that electricity consumption is associated with cooling and fans in larger prestige buildings. Notice in this context that electricity use in three of the 'office boroughs' lies well above the regression line.

It is possible that some further complications are masked in the overall correlation. For instance, it may well be that thermal properties of their envelopes vary in systematic ways with the ages and geometrical properties of buildings, specifically their ratios of exposed surface to volume. Such effects could potentially be examined in further studies.

Meanwhile, the basic result can be compared with the findings of previous work. Rode et al. (2013) looked at the exposed surface areas of residential buildings. They compared this with (modelled) energy use for heating and found a positive correlation for their London building typologies with a coefficient of 0.63 . They also found negative correlations of heat energy demand with density, ground coverage and building height. This last result is somewhat perplexing since energy use for heating can hardly be affected by height as such. It might perhaps be a result of tall buildings being predicted by the modelling to have increased solar exposure, hence greater solar gains? 


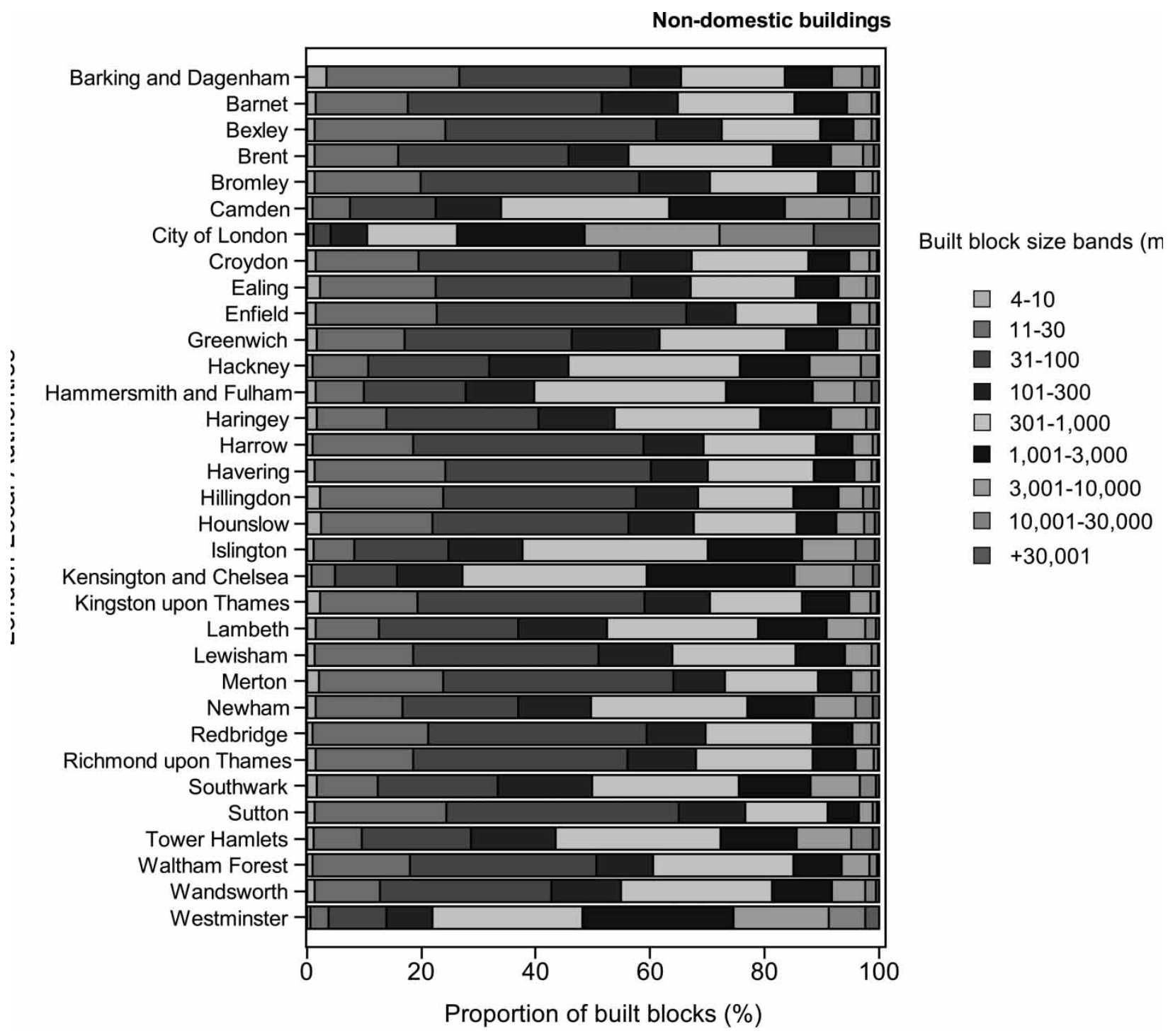

Figure 6 Proportion of non-domestic built blocks by volume size bands for London local authorities

Ratti et al. (2005) found different values for the ratio of surface to volume for their three sample areas in London, Toulouse and Berlin of 0.216, 0.248 and 0.169 , respectively. They did not quantify the relationship with energy use, but remarked on these large differences and their implications for heat loss. Salat (2009) also made comparisons of surface to volume for different parts of Paris and showed that values have increased from the 18th to the 20th centuries with the transition from courtyard developments to freestanding Modernist slabs. These changes were associated with a difference in modelled heat energy use of $58 \mathrm{kWh} / \mathrm{m}^{2} /$ year for the 18 th-century fabric, compared with $100 \mathrm{kWh} / \mathrm{m}^{2} /$ year for the 20thcentury fabric. As mentioned above, Salat's results (and those of Rode et al., 2013) are for residential buildings and therefore not directly comparable with the present work. It should be said that the types of morphology studied by all these authors tended towards the upper end of the scale of building size and density. The current paper shows a rather different picture by plotting values for exposed surface area across the entire city.

\section{Plan depth}

Figure 9 shows the correlation of mean plan depth with gas and electricity demand, respectively, again for all non-domestic buildings in London. The correlation coefficients are again given in Table 3. Here the correlations are weaker, with coefficients of 0.50 (electricity) and 0.38 (gas). As in Figure 7, the 'office boroughs' depart from the regression line. 


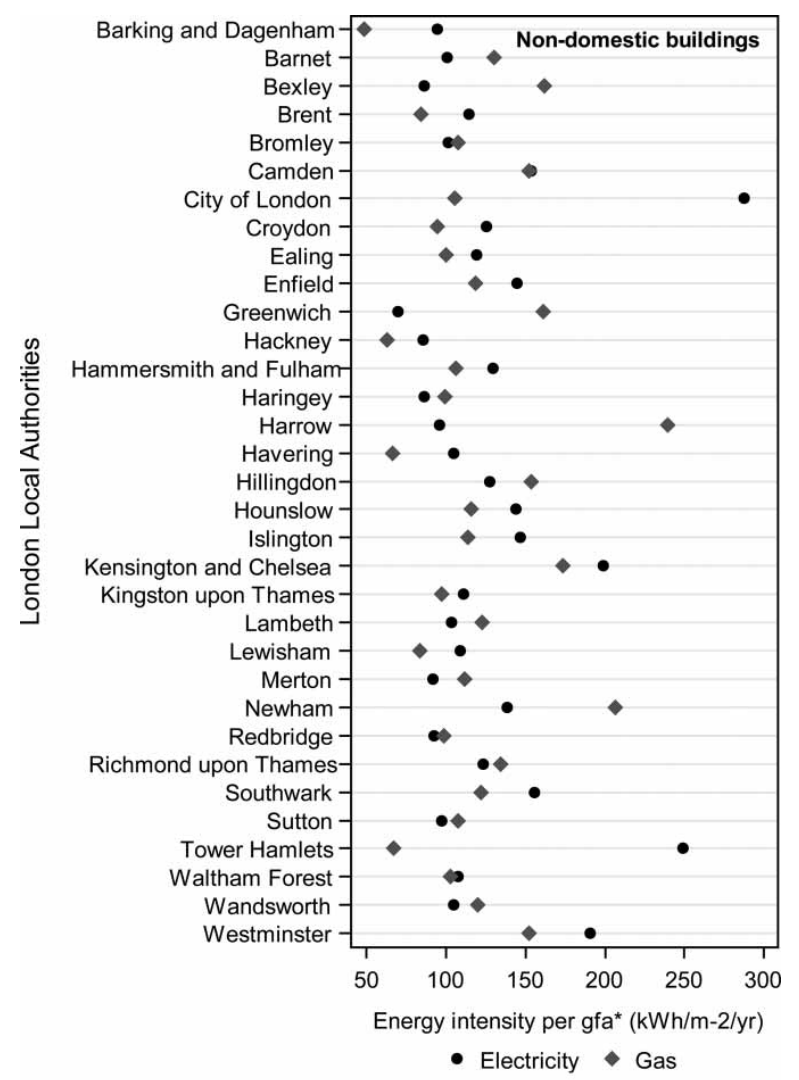

*gfa= gross floor area estimate

Figure 7 Non-domestic electricity and gas intensity per $\mathrm{m}^{2}$ of gross floor area for London's local authorities

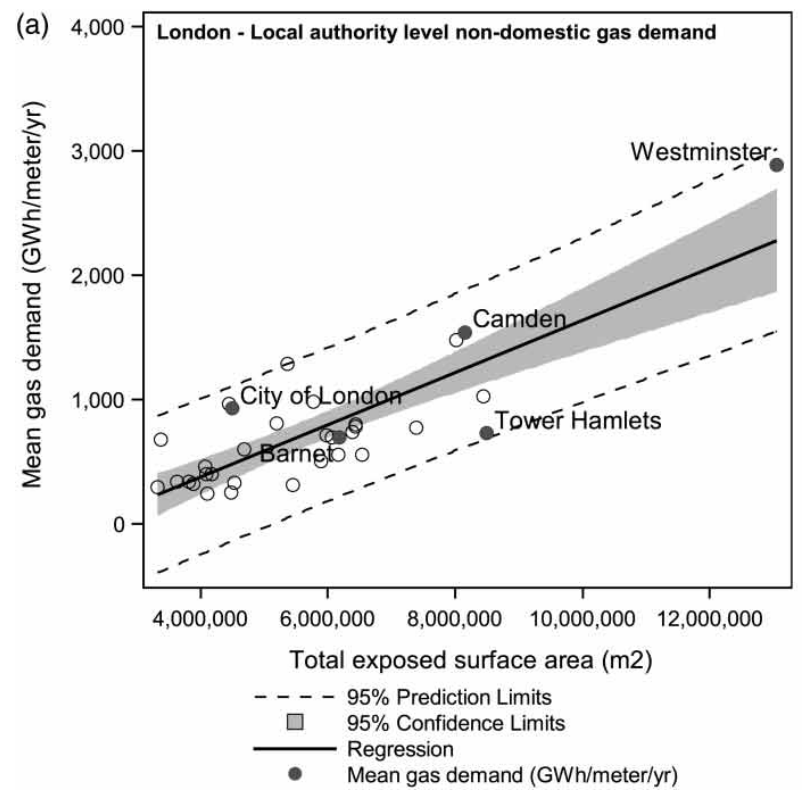

The hypothesis about plan depth, however, relates to multi-storey buildings whose depth effectively requires air-conditioning and permanent artificial lighting. The LT method generally assumes that this dimension is 2 $\times 6=12 \mathrm{~m}$, with perhaps an additional $2 \mathrm{~m}$ for a central corridor, giving $14 \mathrm{~m}$. In the 19th- and early 20th-century literature on office design, a figure of 25 feet $(7.6 \mathrm{~m})$ was repeatedly quoted as the extreme limit of depth for rooms to be lit acceptably from windows. This would imply a total depth, with corridor, of up to $17 \mathrm{~m}$. Empirical measurements of a sample of 19 large office buildings in Swindon (Berkshire) reported in Steadman et al. (2009) show two peaks in the distribution of their plan depths, around 14 and $20 \mathrm{~m}$. This would suggest a first group that (potentially) has natural lighting and natural ventilation, and a second group that is air-conditioned.

Calculations made using simulation models would indicate significant implications of plan depth for energy demand. Steemers (2003), for example, reported an experiment with the LT method to investigate the consequences of increasing the depth of a notional office building from 12 to $24 \mathrm{~m}$. A doubling of energy use was predicted. This assumed that the non-passive areas were mechanically ventilated. For efficient airconditioning the difference was less marked, but energy use was still $20 \%$ greater in the deep building.

Returning to Figure 9, the mean plan depths for almost all boroughs are below $14 \mathrm{~m}$, and only in the City of London and in Barking and Dagenham do they rise above $18 \mathrm{~m}$. Because these are means taken across

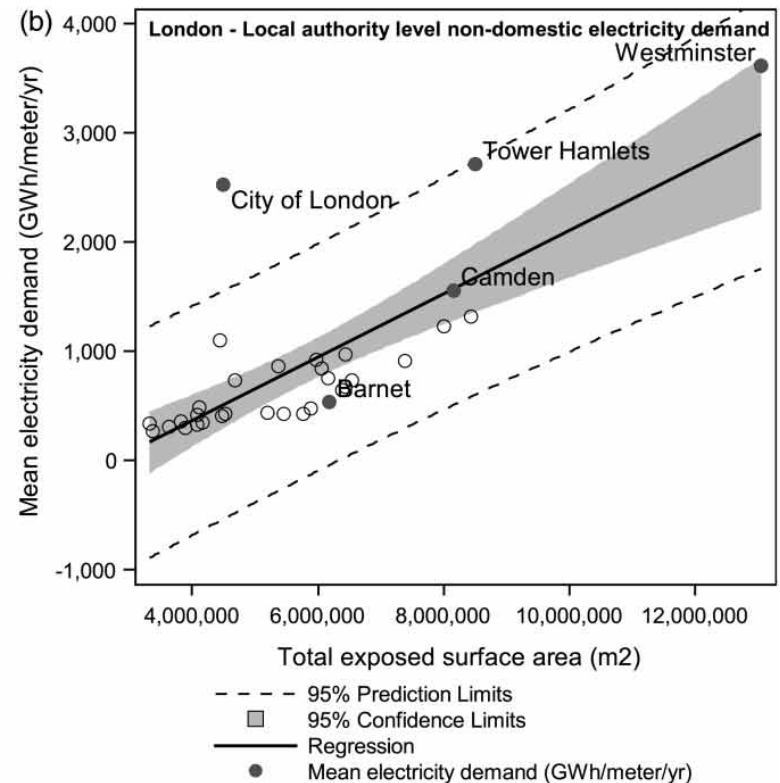

Figure 8 Correlations of total exposed surface area with mean annual gas (a) and electricity (b) demand per meter (GWh/meter/year), for all non-domestic buildings in London at the local authority level 

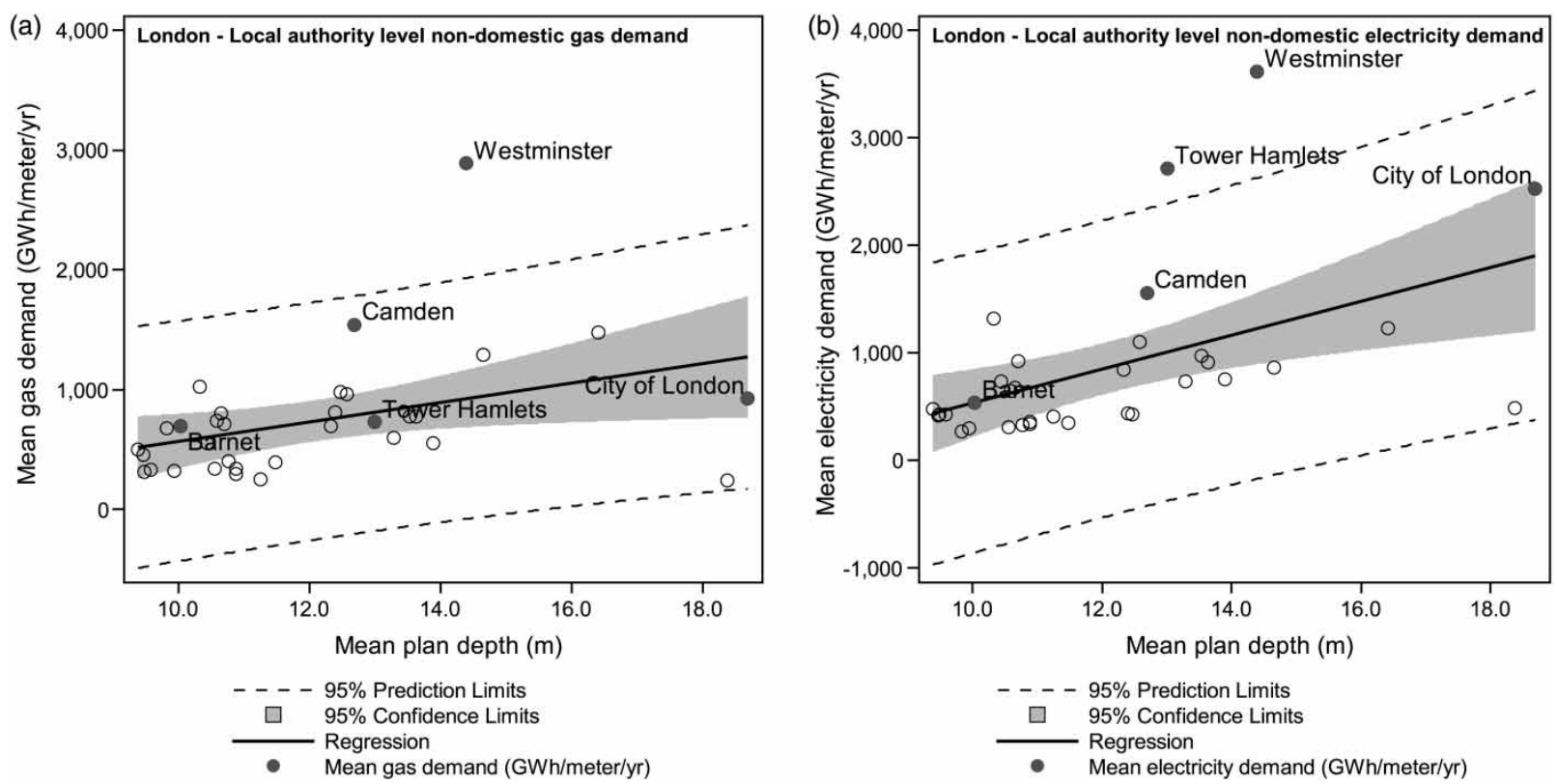

Figure 9 Correlations of plan depth with mean annual gas (a) and electricity (b) demand per meter (GWh/meter/year), for all nondomestic buildings in London at the local authority level

relatively large geographical areas they may of course conceal large local variations in plan depth. Nevertheless, the evidence of this high-level analysis does suggest that very deep buildings tend to be concentrated in just a few boroughs. The City of London in particular is at the same time relatively small in land area and consists predominantly of high-rise office buildings. (The deep plan buildings in Barking and Dagenham are likely to be warehouses and factories.) Therefore, attention is now shifted to this and a small number of other 'office boroughs'.

Previous work computed mean plan depths for building blocks in selected London boroughs in a series of size bands defined by volume. This showed that only in the topmost band, $>30000 \mathrm{~m}^{3}$, did mean depths rise above $14 \mathrm{~m}$. One might expect this result on simple geometrical grounds. Only blocks with this kind of volume would have plans this deep. Imagine a building block with a footprint $20 \times 60 \mathrm{~m}$ and a storey height of $3.5 \mathrm{~m}$. This gives a volume of 4200 $\mathrm{m}^{3}$ per floor. In a block with total volume $30000 \mathrm{~m}^{3}$ this would mean seven floors. Many major office buildings would have larger footprints than this.

Figure 10 shows the distribution of plan depth by LSOA within the City of London and the boroughs of Camden, Tower Hamlets and Westminster. The mean for the City is around $18 \mathrm{~m}$. This can be compared with Figure 11, which gives values for annual electricity use per meter at the MSOA level for the same boroughs. The City has the highest value. The analysis can be investigated in a different way by selecting MSOAs that have high concentrations of particular activities: retail, office, retail plus office or industrial. Figure 12 shows correlations of mean plan depth for

Table 3 Pearson correlation between local authority level energy use and morphological parameters in London

\begin{tabular}{|c|c|c|c|c|c|c|}
\hline \multirow{2}{*}{$\begin{array}{l}\text { Pearson correlation } \\
\text { coefficients, } N=33\end{array}$} & \multicolumn{6}{|c|}{ Prob $>|r|$ under $\mathrm{H} 0$ : rho $=0$} \\
\hline & $\begin{array}{l}\text { Volume } \\
\left(\mathrm{m}^{3}\right)\end{array}$ & $\begin{array}{l}\text { Plan depth } \\
\text { (m) }\end{array}$ & $\begin{array}{l}\text { Exposed } \\
\text { surface area }\left(\mathrm{m}^{2}\right)\end{array}$ & $\begin{array}{l}\text { Height } \\
\text { (m) }\end{array}$ & $\begin{array}{l}\text { Electricity } \\
\text { (kWh/year) }\end{array}$ & $\begin{array}{l}\text { Gas } \\
\text { (kWh/year) }\end{array}$ \\
\hline \multirow[t]{2}{*}{ Electricity (kWh/year) } & 0.92003 & 0.50219 & 0.75935 & 0.43374 & 1 & 0.76066 \\
\hline & $<0.0001^{* * *}$ & $0.0029^{* * *}$ & $<0.0001^{* * *}$ & $0.0117^{* *}$ & & $<0.0001^{* * *}$ \\
\hline \multirow[t]{2}{*}{ Gas (kWh/year) } & 0.88739 & 0.38221 & 0.81731 & 0.5148 & 0.76066 & 1 \\
\hline & $<0.0001^{* * *}$ & $0.0282^{* *}$ & $<0.0001^{* * *}$ & $0.0022^{* * *}$ & $<0.0001^{* * *}$ & \\
\hline
\end{tabular}

Note: ${ }^{*} p<0.1 ; * * p<0.05 ;{ }^{* * *} p<0.01$ 


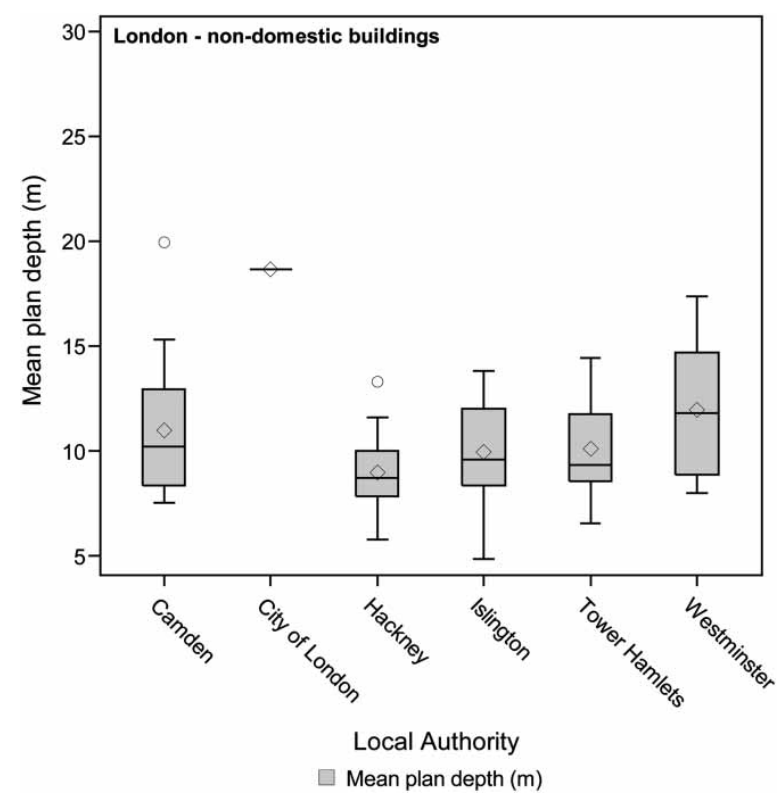

Figure 10 Mean plan depth at the medium level super output area (MSOA) level for selected London local authorities

these areas with annual electricity and gas use per meter. In MSOAs where more than $60 \%$ of total floor space is office use, both electricity and gas consumption are positively correlated with plan depth; and for electricity consumption the slope of the regression line is particularly steep.

This analysis cannot be claimed to be conclusive, but it is at least a suggestive indication of the truth of the second hypothesis that electricity use rises sharply above a threshold of plan depth around $14 \mathrm{~m}$. (There might be additional causes at work here, including the possibility that tall buildings at very high densities - as in the City - are cutting off daylight from the lower storeys, so further raising the demand for artificial lighting. Baker \& Ratti (1999) modelled some effects of this kind.) Recall that these figures only include $28 \%$ of electricity meters, many of which are non-half hourly; as such they should be treated with caution. It would be desirable to pursue these questions at a finer spatial scale; unfortunately, the limitations of the available electricity data make this difficult. Again, as with surface area, there could be confounding effects related to the age and fabric characteristics of buildings. Certainly there would not be deep-plan air-conditioned offices dating from before the 1940s.

The authors cited above who have also looked at plan depth have taken a different approach, and it is not so easy to compare their findings with those of the present paper. Ratti et al. (2005) and Salat (2009) both used GIS tools to draw boundary lines in the plans of buildings modelled in DEMs, set back from the exposed perimeter by some specified distance. These define outer 'passive' zones, which can be lit and ventilated naturally. Any remaining space deeper in the building is designated as 'non-passive' and would have to be artificially lit and air-conditioned. In the two studies in question, the passive depth was taken as $6 \mathrm{~m}$, which is the standard assumption in the LT method used to predict energy use. The volumes of building that are respectively passive and non-passive could then be calculated. All
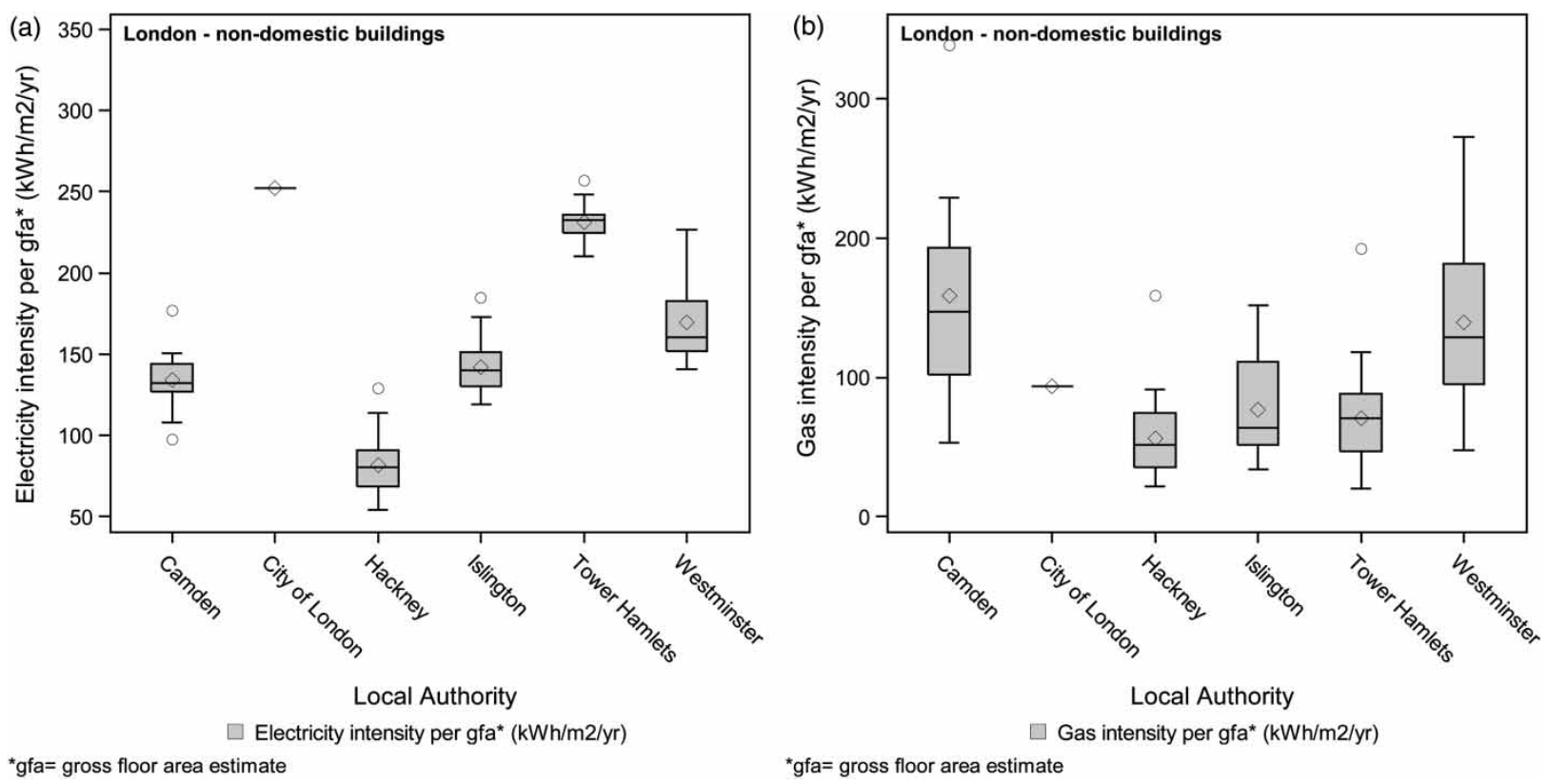

Figure 11 Mean (a) electricity intensity $\left(\mathrm{kWh} / \mathrm{m}^{2} /\right.$ year) and (b) gas intensity ( $\mathrm{kWh} / \mathrm{m}^{2} /$ year) at the medium level super output area (MSOA) level for selected London local authorities 

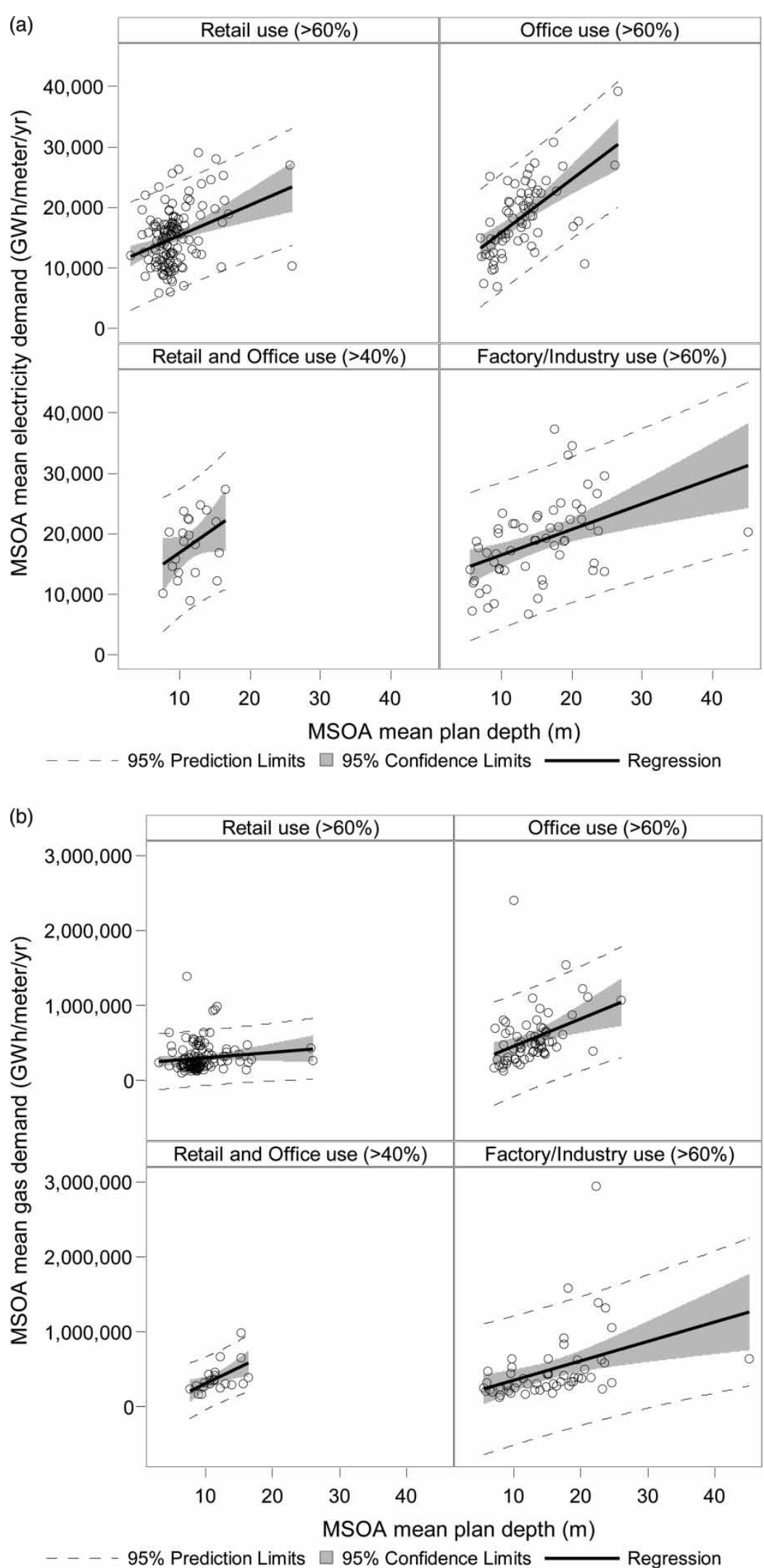

Figure 12 Relationship between medium level super output area (MSOA) level (a) mean electricity demand and (b) mean gas demand and mean MSOA plan depth for areas with a high proportion of a single non-domestic floor space use 
this work was applied to multi-storey buildings where the passive-non-passive distinction may be expected to be significant for energy use.

Ratti et al. (2005) found that the percentage of total building volume made up by passive zones was for $84 \%$ for Toulouse, $77 \%$ for London and $61 \%$ for Berlin. Modelling energy consumption for the nonpassive zones showed that this did not differ greatly between the three cities. However, consumption in passive and non-passive zones combined was somewhat higher in Berlin at $73 \mathrm{kWh} / \mathrm{m}^{2} /$ year compared with values of 67 and $68 \mathrm{kWh} / \mathrm{m}^{2} /$ year for the other two cities. ${ }^{1}$ This does indeed suggest an effect on energy consumption of depth above $12 \mathrm{~m}$. Whether the results can be compared with those of the present paper is another matter. Actual energy consumption data are used in this paper, while Ratti et al.'s figures are modelled. The LT method assumes a priori that the boundary between passive and non-passive zones is $6 \mathrm{~m}$ away from the exposed walls, and consumption is modelled on that assumption. By contrast, the present analysis suggests an effect on electricity use at a somewhat higher value for plan depth, around 18 or $20 \mathrm{~m}$.

\section{Morphological factors' contribution to total energy use}

A correlation of energy use with the exposed surface areas of buildings has been demonstrated, although the full significance of the correlation cannot be assigned

Table 4 Energy, morphology and economic measures: summary statistics for London at the medium level super output area (MSOA) level

\begin{tabular}{|c|c|c|c|c|}
\hline \multirow[t]{2}{*}{ Label } & \multirow{2}{*}{$\begin{array}{l}\text { London } \\
\text { Sum }\end{array}$} & \multicolumn{3}{|c|}{ MSOA level } \\
\hline & & Mean & SD & Median \\
\hline Total building external wall area $\left(\mathrm{m}^{2}\right)$ & 115684534 & 117566 & 159640 & 85386 \\
\hline Total building volume $\left(\mathrm{m}^{3}\right)$ & 706897957 & 718392 & 1466341 & 396801 \\
\hline Total building footprint area $\left(\mathrm{m}^{2}\right)$ & 72939332 & 74125 & 87399 & 50137 \\
\hline Total exposed surface area $\left(\mathrm{m}^{2}\right)$ & 188623866 & 191691 & 238296 & 139492 \\
\hline Count of built blocks $(N)$ & 496951 & 505 & 295 & 445 \\
\hline Total built block height $(\mathrm{m})$ & 570642 & 580 & 339 & 493 \\
\hline Total built block floor space $\left(\mathrm{m}^{2}\right)^{a}$ & 220905612 & 224498 & 458231 & 124000 \\
\hline Mean MSOA plan depth (m) & & 10 & 4 & 9 \\
\hline MSOA gas demand in 2007 (GWh/year) & 224561 & 230 & 637 & 96 \\
\hline Number of allocated non-domestic gas meters & 44756 & 46 & 70 & 30 \\
\hline Mean gas demand in 2007 (kWh/meter/year) & & 473158 & 972309 & 304075 \\
\hline Per capita employee gas use in 2007 (kWh/person) & & 135 & 189 & 95 \\
\hline Gas intensity $\left(\mathrm{kWh} / \mathrm{m}^{2}\right)$ & & 101 & 85 & 80 \\
\hline MSOA electricity demand in 2007 (GWh/year) & 279285 & 284 & 931 & 131 \\
\hline Number of allocated non-domestic electricity meters & 494565 & 503 & 694 & 378 \\
\hline Mean electricity demand in 2007 (kWh/meter/year) & & 48178 & 42667 & 35545 \\
\hline Electricity use per employee in 2007 (kWh/person) & & 163 & 118 & 133 \\
\hline Electricity intensity $\left(\mathrm{kWh} / \mathrm{m}^{2}\right)$ & & 119 & 48 & 114 \\
\hline Proportion of retail floor space $(\%)$ & & 31 & 24 & 28 \\
\hline Proportion of office floor space (\%) & & 21 & 23 & 13 \\
\hline Proportion of warehouse floor space (\%) & & 15 & 22 & 1 \\
\hline Number of employees 2008 & 245404000 & 249394 & 1150805 & 95000 \\
\hline Retail floor space in 2007 ( $\mathrm{m}^{2}$, thousands) & 15507 & 16 & 36 & 7 \\
\hline Office floor space in 2007 ( $\mathrm{m}^{2}$, thousands) & 27591 & 28 & 186 & 4 \\
\hline Rateable value of retail floor space in 2007 ( $£$, thousands) & 103914 & 127 & 64 & 111 \\
\hline Rateable value of office floor space in 2007 ( $£$, thousands) & 75503 & 116 & 42 & 106 \\
\hline
\end{tabular}


Table 5 Multiple regression model results for annual gas and electricity in London at the medium level super output area (MSOA) level

\begin{tabular}{|c|c|c|}
\hline Predictors & Estimated & SE ( $p$-value) \\
\hline $\operatorname{MSOA}(N=983)$ & \multicolumn{2}{|c|}{ Total MSOA gas demand (kWh/year) } \\
\hline Intercept & 8174278 & $3642731(0.0251)$ \\
\hline Number of employees in 2008 & -14.474 & $2.79(<0.0001)$ \\
\hline Total exposed surface area $\left(\mathrm{m}^{2}\right)$ & 162.414 & $36.468(<0.0001)$ \\
\hline Total building floor space $\left(\mathrm{m}^{2}\right)$ & 57.98 & $18.404(0.0017)$ \\
\hline Total MSOA plan depth (m) & -48823 & $13326(0.0003)$ \\
\hline Number of non-domestic gas meters & 165115 & $32649(<0.0001)$ \\
\hline Count of buildings $(N)$ & -12411 & $6204.459(0.0458)$ \\
\hline Total building height (m) & 2274.477 & $7983.093(0.7758)$ \\
\hline Proportion of warehouse floor space (\%) & -29231839 & $6806387(<0.0001)$ \\
\hline Proportion of factory floor space (\%) & 16415659 & $8003783(0.0405)$ \\
\hline Maximum variance inflation factor (VIF) (mean VIF) & \multicolumn{2}{|l|}{$51.97(12.89)$} \\
\hline Condition indices $(\mathrm{Cl})$ & \multicolumn{2}{|l|}{30.97} \\
\hline Adjusted $R^{2}$ & \multicolumn{2}{|l|}{0.6392} \\
\hline $\operatorname{MSOA}(N=983)$ & \multicolumn{2}{|c|}{ Total MSOA electricity demand (kWh/year) } \\
\hline Intercept & -4513232 & $744652(<0.0001)$ \\
\hline Number of employees in 2008 & 1.836 & $0.246(<0.0001)$ \\
\hline Total exposed surface area $\left(\mathrm{m}^{2}\right)$ & 19.385 & $3.266(<0.0001)$ \\
\hline Total building floor space $\left(\mathrm{m}^{2}\right)$ & -5.17 & $1.634(0.0017)$ \\
\hline Total MSOA plan depth $(\mathrm{m})$ & 4832.04 & $1302.48(0.0002)$ \\
\hline Number of allocated non-domestic electricity meters & 15596 & $537.001(<0.0001)$ \\
\hline Count of buildings $(N)$ & 208.945 & $701.176(0.7659)$ \\
\hline Total building height $(\mathrm{m})$ & -4863.912 & $830.07(<0.0001)$ \\
\hline Proportion of retail floor space $(\%)$ & 2923156 & $760024(0.0001)$ \\
\hline Proportion of office floor space (\%) & 1688160 & $981963(0.0865)$ \\
\hline Rateable value of office floor space 2007 ( $£$, thousands) & 11685 & $4964.628(0.0191)$ \\
\hline Rateable value of warehouse floor space 2007 ( $£$, thousands) & -18536 & $7320.305(0.0118)$ \\
\hline Maximum VIF (mean VIF) & $59.21(12.69)$ & \\
\hline Condition indices $(\mathrm{Cl})$ & 25.37 & \\
\hline Adjusted $R^{2}$ & 0.9687 & \\
\hline
\end{tabular}

to this parameter. Some evidence has been provided of an effect of plan depth on electricity use above about $14 \mathrm{~m}$. The question remains as to what degree these factors explain energy consumption, and their significance by comparison with other known drivers. To address this question, MSOA-level gas and electricity demand were used, and two multiple regression models were developed that measure the explanatory power of a series of variables besides the basic morphological measures. These variables include numbers of employees, areas of floor space and proportions of that floor space represented by retail, offices and warehouses (Valuation Office Agency, 2008; Office of National Statistics, 2009). Details are given in Table 4.
As mentioned above, a number of construction features of the non-domestic building stock cannot be accounted for at the analysis level and these results provide only initial indications of the relationships between these variables and energy use. The authors intend to explore this further in future studies using data that may become available from a number of sources including the Valuation Office Agency Summary Valuation (SMV) database of non-domestic buildings.

Initially, a stepwise selection approach was used to determine the predictive strength of variables. This information was then used along with the addition of variables of interest to develop a model with a 
reasonable statistical fit and significance. To ensure that possible collinearity of variables did not overly affect the model, variance inflation factors (VIF) and condition indices (CI) (SAS Institute, 2013) were assessed. In most cases VIF was larger than 5 with most tolerances not larger than 0.25 and all less than 0.5 . When checking the model the authors ensured that condition indices were less than 35 , a general rule of thumb.

Table 5 gives the results of the regression models for total MSOA gas demand $(\mathrm{kWh} /$ year $)$ and total MSOA electricity demand ( $\mathrm{kWh} /$ year). This shows that the model for gas demand has a moderately good fit (adjusted $R^{2}=0.64$ ) using number of employees, total exposed surface area, total building floor space, total plan depth, number of gas meters, number of built blocks, and proportion of warehouse and factory floor space. An increase in the number of employees reduces demand. There is also a negative relationship between the proportion of warehouse floor space and a positive relation with factory space. In terms of morphology, exposed surface area and floor space increase gas demand, while plan depth decreases it.

For electricity demand, there is a very good model fit (adjusted $R^{2}=0.96$ ) using number of employees, total exposed surface area, total building floor space, total plan depth, number of electricity meters, number of built blocks, total built block height, proportion of retail and office floor space, and rateable value of office and warehouse floor space. A greater proportion of retail and office floor space increases electricity demand, as does the rateable value of the office floor space. A greater number of employees increases electricity demand, the opposite of gas demand. This might be explained by areas of high electricity demand being predominantly in the service sector with more employees, while warehousing and manufacturing use more gas with fewer employees. In terms of morphology, exposed surface area and total plan depth increase electricity demand, while floor space reduces it.

Taking the results overall, the regression models show that average plan depth per MSOA is significant in explaining both gas and electricity use. Every additional metre of total MSOA plan depth adds a further $4832 \mathrm{kWh} /$ year of electricity use and reduces gas by $44956 \mathrm{kWh} /$ year. These findings go some way to confirming that MSOAs characterized by deeper built blocks use more electricity and less gas.

There may be some broad implications for policy in the findings reported here. Geometrical parameters might be incorporated into energy benchmarking for nondomestic buildings, a possibility that is explored for schools in another paper in this issue (Hong, Paterson, Mumovic, \& Steadman, 2013). Controls on energy demand will naturally tend to focus on different features and systems, depending on building geometry: lighting and core services in deeper buildings, facade treatment, and ventilation control in shallower buildings. The results presented here may help in framing such policies based on stock-level considerations, not just the design and management of individual buildings.

\section{References}

Baker, N., \& Ratti, C. (1999, November). Simplified urban climate models from medium-scale morphological parameters. In Proceedings of the International Conference on Urban Climatology, ICUC99, Sydney, NSW, Australia.

Batty, M., \& Hudson-Smith, A. (2005). Urban simulacra. Architectural Design, 75, 42-47.

Brown, F. E., Rickaby, P. A., Bruhns, H., \& Steadman, P. (2000). Surveys of nondomestic buildings in four English towns. Environment and Planning B: Planning and Design, 27, 11-24.

Department of Energy and Climate Change (DECC). (2009). Guidance note for the DECC MLSOA/IGZ and LLSOA electricity and gas consumption data. London: DECC.

Department of Energy and Climate Change (DECC). (2012). Energy consumption in the United Kingdom 2012: Service sector energy consumption. London: DECC. Retrieved from https://www.gov.uk/government/ publications/energy-consumption-in-the-uk

HM Government. (2013). Land use statistics (generalised land use database). Retrieved from http://data.gov.uk/dataset/ land_use_statistics_generalised_land_use_database. Accessed January 2013.

Hong, S.-M., Paterson, G., Mumovic, D., \& Steadman, P. J. (2013). Improved benchmarking comparability for energy consumption in schools. Building Research \& Information, doi: 10.1080/09613218.2013.814746.

Liddiard, R. (2013). Room scale profiles of space use and electricity consumption in non-domestic buildings. Building Research \& Information, doi: 10.1080/09613218.2013.817112.

Office of National Statistics (ONS). (2009). Business Register and Employment Survey (BRES) 2008. London: ONS.

Ratti, C., Baker, N., \& Steemers, K. (2005). Energy consumption and urban texture. Energy and Buildings, 37, 762-776.

Rode, P., Keim, C., Robazza, G., Viejo, P., \& Schofield, J. (2013, in press). Cities and energy: urban morphology and residential heat energy demand. Environment and Planning B: Planning and Design.

Salat, S. (2009). Energy loads, $\mathrm{CO}_{2}$ emissions and building stocks: morphologies, typologies, energy systems and behaviour. Building Research \& Information, 37(5-6), 598-609.

SAS Institute. (2013). SAS 9.2 user's guide second edition. Cary, NC: SAS Institute, Inc.

Steadman, P., Evans, S., \& Batty, M. (2009). Wall area, volume and plan depth in the building stock. Building Research \& Information, 37(5-6), 455-467.

Steemers, K. (2003). Energy and the city: density, buildings and transport. Energy and Buildings, 35, 3-14.

Valuation Office Agency. (2008). Commercial and industrial floorspace and rateable value statistics 2007 (2005 revaluation). London: Valuation Office Agency

\section{Endnote}

${ }^{1}$ The units for these figures in Ratti et al. (2005), figure 21, p. 773 , are incorrect. They are given as $\mathrm{kWh} / \mathrm{m}^{2} /$ year, but are in fact $\mathrm{MWh} / \mathrm{m}^{2} /$ year. 